\title{
The association of trajectories of protein intake and age-specific protein intakes from 2 to 22 years with BMI in early adulthood
}

\author{
Melecia Wright ${ }^{1 *}$, Daniela Sotres-Alvarez ${ }^{2}$, Michelle A. Mendez ${ }^{1}$ and Linda Adair ${ }^{1}$ \\ ${ }^{1}$ Department of Nutrition, University of North Carolina at Chapel Hill, Chapel Hill, NC 27599, USA \\ ${ }^{2}$ Department of Biostatistics, University of North Carolina at Chapel Hill, Chapel Hill, NC 27599, USA \\ (Submitted 30 September 2016 - Final revision received 24 January 2017 - Accepted 7 February 2017 - First published online 28 March 2017)
}

\section{Abstract}

No study has analysed how protein intake from early childhood to young adulthood relate to adult BMI in a single cohort. To estimate the association of protein intake at 2,11, 15, 19 and 22 years with age- and sex-standardised BMI at 22 years (early adulthood), we used linear regression models with dietary and anthropometric data from a Filipino birth cohort (1985-2005, $n$ 2586). We used latent growth curve analysis to identify trajectories of protein intake relative to age-specific recommended daily allowance (intake in $\mathrm{g} / \mathrm{kg}$ body weight) from 2 to 22 years, then related trajectory membership to early adulthood BMI using linear regression models. Lean mass and fat mass were secondary outcomes. Regression models included socioeconomic, dietary and anthropometric confounders from early life and adulthood. Protein intake relative to needs at age 2 years was positively associated with BMI and lean mass at age 22 years, but intakes at ages 11,15 and 22 years were inversely associated with early adulthood BMI. Individuals were classified into four mutually exclusive trajectories: (i) normal consumers (referent trajectory, $58 \%$ of cohort), (ii) high protein consumers in infancy (20\%), (iii) usually high consumers (18\%) and (iv) always high consumers (5\%). Compared with the normal consumers, 'usually high' consumption was inversely associated with BMI, lean mass and fat mass at age 22 years whereas 'always high' consumption was inversely associated with male lean mass in males. Proximal protein intakes were more important contributors to early adult BMI relative to early-childhood protein intake; protein intake history was differentially associated with adulthood body size.

Key words: Proteins: Life-course epidemiology: Diets: Longitudinal data analyses: BMI

Conventionally, proximal behaviours are thought to strongly modify disease risk but examining early life factors may yield intriguing insights into the origins of later disease ${ }^{(1)}$. For example, clarifying how the infant diet may influence later obesity risk is important as it may highlight a window of opportunity for designing interventions that promote health across the life course. In particular, the role of dietary protein in modifying obesity risk deserves further attention ${ }^{(2)}$.

During infancy, adequate protein intake is critical to growth and development ${ }^{(3)}$. Deficiencies in protein and/or other macronutrients result in failure to attain age-appropriate height and weight ${ }^{(4)}$. In resource-poor settings, diets limited in high-quality or animal protein exacerbate risk of undernutrition ${ }^{(5)}$. The role of protein in reducing undernutrition is well established; however, studies from the Developmental Origins of Health and Disease (DOHaD) perspective suggest that infant protein intake may promote later obesity via its effects on adipocyte differentiation and adipogenesis ${ }^{(6)}$ and the timing of the adiposity rebound $^{(7,8)}$. In fact, studies from higher-income settings have found independent associations of infant protein intake with later obesity ${ }^{(5)}$. Reviews of these studies acknowledge convincing evidence ${ }^{(9)}$ that protein intake in early life is positively associated with risk of obesity, but the mechanisms are yet to be confirmed ${ }^{(10)}$.

Whereas protein intake in early life may have these long-term effects on later risk of obesity, the role of proximal protein intake (in adulthood) merits attention as well, as adulthood protein intake also contributes to adulthood obesity risk. Proteins may exert beneficial effects on adult metabolic risk by promoting satiety (thus reducing overeating), increasing thermogenesis (which promotes fat metabolism) and improving glucose metabolism ${ }^{(11,12)}$. In fact, the 'protein leveraging' hypothesis stresses that the satiating effects of protein strongly regulate total energy intake, and thus, modifying dietary protein may be one approach to curb the obesity epidemic ${ }^{(2,13)}$. 'Nutrition transition' refers to the increased consumption of refined carbohydrates and fats that has occurred in recent decades; this transition has diversified diets in several low- and middle- income countries ${ }^{(14-17)}$. Proponents of the protein leveraging hypothesis suggest that the reduced protein-density

Abbreviations: CLHNS, Cebu Longitudinal Health and Nutrition Survey; RDA, recommended daily allowance.

* Corresponding author: Dr M. Wright, email meleciaw@gmail.com 
of these diversified diets may induce overeating to meet daily protein requirements ${ }^{(2,13)}$.

Although a review of the literature yields these important examples of how protein intake may modify obesity risk in an age-dependent manner, no study has fully accounted for the role of dietary protein patterns in modifying obesity risk. When studies focus on protein intakes in distinct time periods, this approach neglects the potential roles of cumulative protein intake patterns across the life course. In light of the rapid westernisation of traditional diets worldwide ${ }^{(17)}$, an individual may experience periods of excess, adequate and insufficient protein intake in a single lifespan ${ }^{(18,19)}$. It is unclear how combinations of such exposures across the life course may influence adult BMI. Moreover, outside of infancy, other sensitive periods may exist but are yet to be identified; hence, studying pubescence or adolescence could also grant important insights ${ }^{(20,21)}$. Thus, we employed a life-course approach ${ }^{(22,23)}$ to analyse how protein intake affects later body composition. We asked two main questions. First, are there periods of the life course during which protein intake may modify later BMI, fat mass and lean mass? To this end, we estimated how protein intake in early childhood, pubescence, adolescence and young adulthood was associated with later BMI, fat mass and lean mass. We expected that protein intake in early childhood would be positively associated with adulthood BMI and that protein intakes at later ages would be inversely associated with adult BMI, fat mass and lean mass. Second, does life history of protein intake differentially relate to later BMI? We explored how histories of protein intake related to body size in young adulthood. We hypothesised that there would be distinct trajectories of protein intake, and that these trajectories would be differentially associated with BMI, fat mass and lean mass in young adulthood.

\section{Methods \\ Study population}

The Cebu Longitudinal Health and Nutrition Survey (CLHNS) follows a birth cohort of infants born in Cebu, Philippines ${ }^{(24)}$. Detailed dietary and anthropometric data were collected at bimonthly intervals between birth and 24 months (1983-1986), and in five subsequent post-infancy surveys: 1991-1992, 1994-1995, 1998-1999, 2002 and 2005 ${ }^{(24)}$. There were 3080 singleton infants at birth and 1885 individuals in 2005.

\section{Diet}

Diet was assessed using $24 \mathrm{~h}$ dietary recalls, one recall for each bimonthly survey from birth to 24 months and two recalls for surveys from 11 years onwards. The means of the dietary intakes reported at 22 and 24 months were used to estimate usual intake at age 2 years. Protein intake was estimated using the Filipino Food Composition Tables ${ }^{(25)}$. Nutrients from breastmilk were not quantified; thus, dietary data at 22 and 24 months only account for estimated nutrient intake from complementary foods and underestimate total nutrient intake in $14 \%$ infants that were still being breastfed. Analyses presented here include surveys that collected recall data from age 22 and
24 months and 11, 15, 19 and 22 years. The 1991 survey employed an FFQ which systematically overestimated macronutrient intake data and so it was omitted from these analyses.

\section{Primary exposure}

The primary exposure was 'protein relative to needs'; this was the difference between estimated protein intake and the agespecific recommended daily allowance (RDA) of protein $(\mathrm{g} / \mathrm{kg}$ body weight). An absolute specification of protein intake would have been inappropriate and misleading as heavier people have greater energy needs, and thus, tend to consume more macronutrients. Our specification of protein intake $(\mathrm{g} / \mathrm{kg}$ body weight) more appropriately conveys whether a surplus (if positive) or deficit (if negative) of protein intake was consumed relative to individual needs. RDA for years 2, 11, 15,19 and 22 were $1.05,0.95,0.85,0.80$ and $0.80 \mathrm{~g} / \mathrm{kg}$ body weight, respectively ${ }^{(3)}$.

\section{Confounders and key covariates}

Statistical models were adjusted for variables that might potentially confound the association of protein intake with later BMI, lean mass and fat mass, given their hypothesised associations with both protein intake and body composition. Models also included variables that were strongly associated with body composition at age 22 years to clarify whether observed associations between protein intake trajectories and body composition were independent of these variables. We included sex, factors from the time of the offspring's birth (offspring weight $(\mathrm{kg})$, maternal education (years) and maternal height $(\mathrm{cm})$ ), factors from early childhood (duration of breast-feeding (months), a household assets score at age 2 years and offspring BMI $\left(\mathrm{kg} / \mathrm{m}^{2}\right)$ at age 2 years) and variables related to the offspring at age 22 years (household assets, physical activity level, education (years), energy intake ( $4184 \mathrm{~kJ}$ (1000 kcal) units) and residuals of carbohydrate and fat intake). The composite score of household assets ranged from 0 to 11 and was based on individual possession of the following: electricity, house, material of house, air conditioner, television, tape recorder, refrigerator, electric fan, jeepneys (customised taxi jeeps), car and clothing iron. Physical activity at age 22 years was a binary variable based on normal (600-1000 metabolic equivalent minutes (METS)/week) or low (<600 METS/week) reported activity, following the WHO recommendations ${ }^{(26)}$. We did not include timevarying factors for interim years (ages 11, 15 or 19 years) either because they were unavailable (physical activity), were presumably on the pathway between protein intake and early adulthood BMI (interim BMI or macronutrients) or had negligible effects on regression coefficients when included (interim asset scores).

\section{Primary outcome}

BMI $\left(\mathrm{kg} / \mathrm{m}^{2}\right)$ at age 22 years was the primary outcome. Lean mass (kg) and fat mass ( $\mathrm{kg}$ ) at age 22 years were secondary outcomes. Weight, height and skinfold thicknesses were measured by trained personnel. Body fat percentage was calculated from skinfold thicknesses using equations validated in Asian 
populations $^{(27)}$. Fat mass (kg) was then calculated as \%body fat $\times$ weight $(\mathrm{kg})$; lean mass $(\mathrm{kg})$ was the difference between body weight and fat mass. All three outcomes were stratified by sex and then standardised to the mean for males and females in the sample to aid in interpretability. The $\mathrm{kg}$ or $\mathrm{kg} / \mathrm{m}^{2}$ equivalents are provided in-text for context. Pregnant women were omitted from all analyses of body composition.

\section{Statistical analyses}

Age-specific protein intake and standardised BMI, lean mass and fat mass at age 22 years. To fulfil the first aim of this study we assessed the association of age-specific protein intakes relative to needs with three measures of body size at 22 years using multivariable linear regression analyses. Protein intakes relative to needs at ages 2, 11, 15, 19 and 22 years were simultaneously included in the regression models as independent variables. The protein intake variables were not significantly correlated with each other (variance inflation factors <10). To aid in the interpretation of estimates, we reported changes associated with $20 \%$ increases in protein relative to needs - a modest increase that is within the range of realistic dietary changes. (e.g. a $20 \%$ increase is equivalent to an additional $2 \mathrm{~g}$ of protein $(60 \mathrm{ml}$ of whole milk) for a 2-year-old who weighs $10 \mathrm{~kg}$ or an additional $9 \mathrm{~g}$ of protein $(265 \mathrm{ml}$ of whole milk) for a 22-year-old who weighs $55 \mathrm{~kg}$.) Product terms between sex and protein intake relative to needs were included to assess sex-specific associations. Analyses were adjusted for the above-detailed anthropometric, dietary and socioeconomic covariates. The three outcomes, standardised BMI, standardised lean mass and standardised fat mass, were dependent variables.

Derivation of protein intake trajectories. To meet the second objective of this study, we investigated whether history of protein intake was differentially associated with later BMI. This involved first classifying individuals with similar protein intake trajectories into groups, and then relating trajectory membership to later BMI.

We used finite mixture models to classify the cohort's heterogeneous patterns of relative protein intake ( $\mathrm{g} / \mathrm{kg}$ body weight) from 2 to 22 years into latent growth curves or trajectories. This statistical approach assumes that individuals classified within the same trajectory have homogenous protein intake, and that their protein intake patterns vary from those of individuals assigned to other trajectories ${ }^{(28,29)}$.

An a priori criterion was established to select the optimal number of trajectories. We considered: (i) parsimony: we would select the simplest number $(n)$ of trajectories needed to describe meaningful patterns in the data, and thus, a fivetrajectory solution would be the largest tested, (ii) reasonable subset sizes: we would reduce the possibility of capturing idiosyncratic or anomalous protein intake patterns ${ }^{(30)}$ by ensuring that trajectories represented at least $3 \%$ of the cohort and (iii) Bayesian information Criteria (BIC). For a given model with $n$ trajectories, we modelled relative protein intake by specifying cubic, quadratic or linear trajectories. If $P$ values exceeded $0 \cdot 10$ for the higher order term then a lower order model was preferred for the $n$-trajectory model ${ }^{(31,32)}$. A similar process was used to select the optimal orders for a model with $n+1$ trajectories. Next, the a priori criterion was used to compare models for $n-n+1$ trajectories and the final model was selected. Trajectories were derived using the traj command in Stata $14^{(28)}$.

One-way ANOVA and $\chi^{2}$ tests were employed to assess whether the distribution of covariate characteristics in early life varied significantly by trajectory membership.

Trajectory of relative protein intake and standardised BMI, lean mass and fat mass at age 22 years. Multivariable linear regression models were then used to estimate the association of the independent variable, protein intake trajectory membership, with the three outcomes (standardised BMI, lean mass and fat mass at age 22 years). Product terms between sex and protein intake trajectories were included to elucidate sex-specific associations. Regression models also included the abovedescribed anthropometric, dietary and socioeconomic factors from early life and adulthood. We used post-estimation Wald tests to compare outcomes between trajectories for males and females separately. (e.g. we assessed whether the difference between the BMI of females aged 22 years assigned to a given trajectory was significantly different from that of females assigned to a referent trajectory.)

We also assessed the potential for bias due to attrition by conducting Heckman ${ }^{(33)}$ selection models. These two-stage regression models involve (i) using a set of baseline covariates (maternal, household and community-level factors) as independent variables that relate to the outcome of being present in the survey at age 22 years and (ii) using the independent variables (protein intake variables, interaction terms and confounders) to predict the body size outcome (such as BMI). The model compares residuals from both the selection model and the prediction model, and if residuals are uncorrelated then the potential for selection bias in the standard regression coefficients may be mitigated. We compared coefficients from the Heckman selection models with the standard regression models.

\section{Results}

Descriptive demographic and dietary details in the Cebu Longitudinal Health and Nutrition Survey

On average, mothers in the CLHNS had received approximately 8 years of formal education at the time of the offspring's birth (Table 1). The sample had a relatively low urbanicity score in early life but, because of migration to more urban areas as well as urbanisation of all communities, the sample became more urban by age 22 years. By age 22 years, offspring had spent an average of 11 years in formal education and had a mean BMI that was in the normal-weight category. Mean protein intake exceeded the RDA at every survey. Across all surveys, meat and poultry, seafood and grains accounted for $>75 \%$ of all protein consumed (data not shown). All other protein sources (such as eggs, dairy products, legumes and seeds) contributed $<10 \%$ to protein intake. 
Table 1. Select demographic and dietary characteristics from birth to 22 years Cebu Longitudinal Health and Nutrition Survey (1983-2005) (Mean values and standard deviations)

\begin{tabular}{|c|c|c|c|c|c|c|c|c|c|c|c|c|}
\hline \multirow[b]{2}{*}{ Covariates } & \multicolumn{2}{|c|}{ Birth } & \multicolumn{2}{|c|}{ Age 2 years } & \multicolumn{2}{|c|}{ Age 11 years } & \multicolumn{2}{|c|}{ Age 15 years } & \multicolumn{2}{|c|}{ Age 19 years } & \multicolumn{2}{|c|}{ Age 22 years } \\
\hline & Mean & SD & Mean & SD & Mean & SD & Mean & SD & Mean & SD & Mean & SD \\
\hline$n$ & \multicolumn{2}{|c|}{3080} & \multicolumn{2}{|c|}{2456} & \multicolumn{2}{|c|}{2181} & \multicolumn{2}{|c|}{2089} & \multicolumn{2}{|c|}{2023} & \multicolumn{2}{|c|}{1888} \\
\hline Maternal education (years) & 7.56 & 3.72 & & & & & & & & & & \\
\hline Maternal height $(\mathrm{cm})$ & $150 \cdot 56$ & $5 \cdot 00$ & & & & & & & & & & \\
\hline Household assets (range $1-11)^{\star}$ & 2.51 & 1.94 & 2.65 & 1.96 & $4 \cdot 00$ & $2 \cdot 19$ & $4 \cdot 68$ & $2 \cdot 17$ & $5 \cdot 17$ & 2.09 & $5 \cdot 23$ & 2.03 \\
\hline Household urbanicity (range $0-70)^{*}$ & $30 \cdot 58$ & $12 \cdot 61$ & $28 \cdot 41$ & $13 \cdot 69$ & 35.97 & $13 \cdot 21$ & $39 \cdot 08$ & $13 \cdot 69$ & 41.96 & $13 \cdot 84$ & 41.04 & $13 \cdot 35$ \\
\hline Offspring weight $(\mathrm{kg})^{*}$ & 3.00 & 0.42 & $9 \cdot 78$ & $1 \cdot 23$ & 28.46 & 6.08 & 44.48 & $7 \cdot 88$ & $49 \cdot 79$ & 8.69 & 51.62 & $9 \cdot 99$ \\
\hline Offspring length/height $(\mathrm{cm})^{*}$ & $49 \cdot 07$ & 2.07 & $79 \cdot 15$ & 3.68 & $133 \cdot 81$ & $7 \cdot 51$ & 153.97 & $7 \cdot 81$ & $157 \cdot 15$ & $8 \cdot 13$ & $157 \cdot 44$ & $8 \cdot 21$ \\
\hline Offspring BMI $\left(\mathrm{kg} / \mathrm{m}^{2}\right) \star$ & & & $15 \cdot 56$ & $1 \cdot 23$ & $15 \cdot 75$ & $2 \cdot 06$ & 18.69 & 2.48 & $20 \cdot 11$ & $2 \cdot 76$ & $20 \cdot 74$ & $3 \cdot 15$ \\
\hline Offspring lean mass $(\mathrm{kg})$ & & & & & & & & & & & $39 \cdot 36$ & $9 \cdot 22$ \\
\hline Offspring fat mass $(\mathrm{kg})$ & & & & & & & & & & & $12 \cdot 27$ & $5 \cdot 36$ \\
\hline Offspring education (years) & & & & & & & & & & & $10 \cdot 84$ & 3.65 \\
\hline Duration of breast-feeding (months) & & & $12 \cdot 39$ & $8 \cdot 32$ & & & & & & & & \\
\hline Male $(\%)$ & 52.99 & & & & & & & & & & & \\
\hline Energy intake $(\mathrm{kJ})^{\star}$ & & & $2985 \cdot 62$ & $1503 \cdot 48$ & $7195 \cdot 31$ & $3439 \cdot 04$ & $6644 \cdot 15$ & $2815 \cdot 12$ & $7832 \cdot 28$ & 3434.39 & $8117 \cdot 46$ & $3481 \cdot 84$ \\
\hline Energy intake (kcal)* & & & 713.58 & $359 \cdot 34$ & $1719 \cdot 72$ & 821.95 & 1587.99 & $672 \cdot 83$ & 1871.96 & $820 \cdot 84$ & $1940 \cdot 12$ & $832 \cdot 18$ \\
\hline Protein ( $\mathrm{g} / \mathrm{kcal}$ body weight) ${ }^{*}$ & & & 2.04 & 1.05 & 1.96 & 0.96 & $1 \cdot 10$ & 0.49 & 1.36 & 0.63 & 1.44 & 0.67 \\
\hline Protein $(g)^{\star}$ & & & $16 \cdot 94$ & $8 \cdot 31$ & $54 \cdot 58$ & $26 \cdot 36$ & $48 \cdot 46$ & 22.03 & $67 \cdot 01$ & $31 \cdot 31$ & $73 \cdot 23$ & 34.66 \\
\hline Protein ( $\%$ of energy intake) & & & $9 \cdot 87$ & 3.85 & $13 \cdot 06$ & 3.46 & $12 \cdot 37$ & 2.91 & $14 \cdot 64$ & 3.92 & $15 \cdot 33$ & $4 \cdot 25$ \\
\hline Fat $(g)^{*}$ & & & $11 \cdot 80$ & $14 \cdot 60$ & $24 \cdot 32$ & $20 \cdot 67$ & 41.43 & $32 \cdot 30$ & $61 \cdot 11$ & 45.42 & $51 \cdot 68$ & 39.87 \\
\hline Carbohydrates $(\mathrm{g})^{*}$ & & & $127 \cdot 36$ & 51.69 & $200 \cdot 27$ & $79 \cdot 47$ & $252 \cdot 37$ & 101.58 & 259.95 & $111 \cdot 12$ & 263.62 & $109 \cdot 31$ \\
\hline
\end{tabular}

* ANOVA shows that means vary significantly across the survey years shown $(P<0.05)$

\section{Age-specific intakes of protein were differentially} associated with body composition at age 22 years

Protein intake was differentially associated with body composition in an age-dependent manner (Fig. 1). A $20 \%$ higher intake of protein (relative to age-specific RDA ( $\mathrm{g} / \mathrm{kg}$ body weight)) consumed at age 2 years was modestly but positively associated with females' BMI (0.020 sD; 95\% CI 0.006, 0.033; $\beta$ equivalent to $0.06 \mathrm{~kg} / \mathrm{m}^{2}$ ) and females' lean mass (0.014 sD; $95 \%$ CI $0.001,0.028$ or $\beta 0.06 \mathrm{~kg}$ ) at 22 years.

At all other ages, protein intake relative to needs was mostly inversely associated with body composition at age 22 years; the strength and magnitude of these associations varied with age. The largest of these estimated associations were for protein consumed at age 22 years. A $20 \%$ higher intake of protein relative to needs was associated with lower lean mass $(-0.147 \mathrm{sD} ; 95 \% \mathrm{CI}-0 \cdot 165,-0 \cdot 129$ or $\beta-0.3 \mathrm{~kg}$ in females and $-0.175 \mathrm{SD} ; 95 \% \mathrm{CI}-0.197,-0.153$ or $\beta-0.51 \mathrm{~kg}$ in males), fat mass $(-0.155 \mathrm{sD} ; 95 \% \mathrm{CI}-0 \cdot 175,-0 \cdot 136$ or $\beta-0.4 \mathrm{~kg}$ in females and $-0 \cdot 161 \mathrm{sD} ; 95 \% \mathrm{CI}-0 \cdot 184,-0 \cdot 137$ or $\beta-0.4 \mathrm{~kg}$ in males) and BMI at 22 years $(-0.164 \mathrm{sD} ; 95 \% \mathrm{CI}-0.183,-0.145$ or $\beta-0.3 \mathrm{~kg} / \mathrm{m}^{2}$ and $-0.177 \mathrm{sD} ; 95 \%$ CI $-0.201,-0.153$ or $\beta-0.3 \mathrm{~kg} / \mathrm{m}^{2}$ in females and males, respectively). The Heckman-corrected findings were similar to these results.

\section{Derivation of protein intake trajectories using latent class growth curve analyses}

The four-trajectory model was selected because it had optimal parsimony, interpretability and fit statistics (BIC $=-12$ 006.93). Spaghetti plots from random subsets of each trajectory are displayed (Fig. 2(a) and (d)). All latent trajectories of mean protein intake for the 2586 individuals in the CLHNS are shown in Fig. 2(f). The referent trajectory ( $58 \%$ of the sample) was characterised by 'normal consumers' whose protein intake was just slightly higher than recommended (Fig. 2(a)). The second trajectory $(20 \%)$ was characterised by 'high consumers during infancy' who tended to exceed the RDA at age 2 years but had relatively normal intakes thereafter (Fig. 2(b)). The 'usually high consumers' (18\%) tended to exceed the RDA before age 19 years, and had markedly high intakes at age 11 years (Fig. 2(c)). The smallest trajectory (5\%) was characterised by 'always high consumers' who had very high protein intakes at age 2 years and high protein intakes thereafter (Fig. 2(d)). All mean intakes for derived trajectories exceeded the RDA (Fig. 2 (e)). Although trends were similar for trajectories of absolute protein intake (with normal consumers generally consuming the lowest grams of protein in each survey), the distinctions were not as marked (Fig. 2(f)).

\section{Early life characteristics vary by trajectory}

Early life characteristics varied significantly by trajectory (Table 2). 'Normal consumers' lived in households with fewer assets at age 2 years, lived in more rural communities and had the longest average duration of breast-feeding. Maternal education at baseline was highest for the groups of 'high consumers during infancy' and 'always high' consumers. The 'usually high' consumers had a disproportionately more males whereas members of 'always high' consumers had the lowest mean birth weight and BMI at age 2 years.

\section{Trajectories of protein intake relative to needs are differentially associated with BMI at age 22 years}

Trajectory membership was differentially associated with body composition at age 22 years (Fig. 3). Female or male normal 


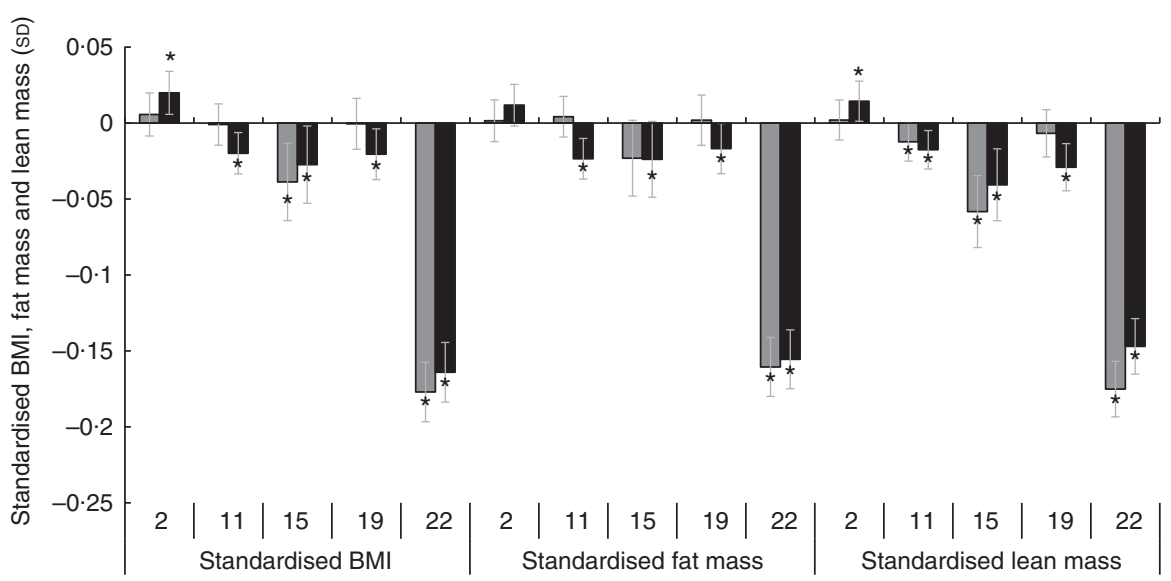

Age (years)

Fig. 1. Protein intakes relative to needs were differentially associated with fat mass, lean mass and BMI at age 22 years in an age-dependent manner in the Cebu Longitudinal Health and Nutrition Survey (CLHNS). Bars represent the change in early adulthood standardised BMI, fat mass or lean mass, associated with a $20 \%$ increase in protein intake at the indicated age relative to the recommended daily allowance for that age. BMl, fat mass and lean mass at age 22 years were standardised to the mean of the sex-stratified sample of the CLHNS. Coefficients were derived from the linear regression of age-specific protein intakes relative to needs on the standardised outcomes and adjusted for characteristics at birth (offspring weight, maternal education and maternal height), characteristics at age 2 years (offspring BMI and household assets), characteristics from age 22 years (offspring education and assets, physical activity level, carbohydrate residuals, fat residuals and energy intake). $\square$, Males; $\square$, females. ${ }^{*} P<0.05$.
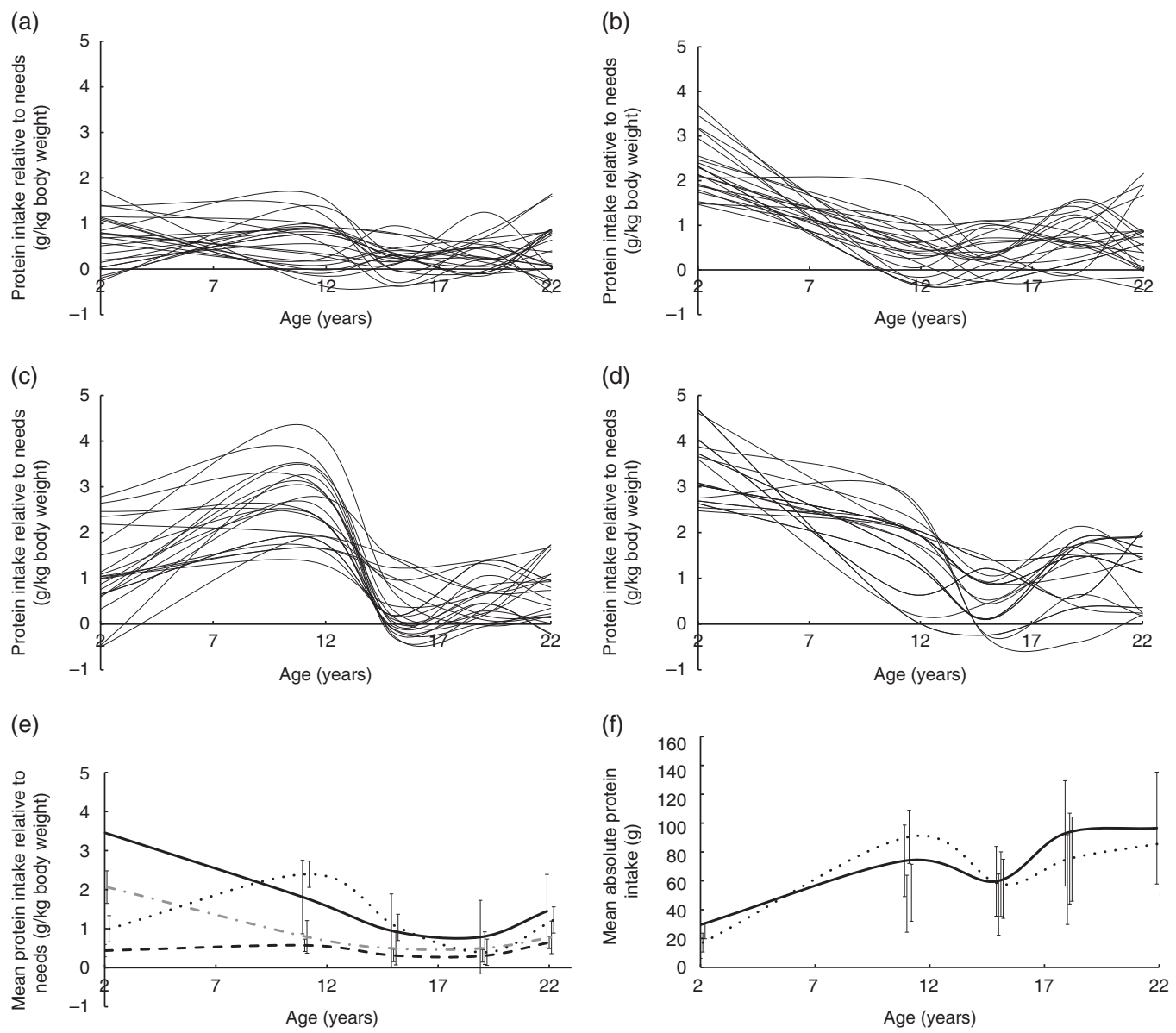

Fig. 2. Trajectories of protein intakes relative to needs from 2 to 22 years in the Cebu Longitudinal Health and Nutrition Survey ( $n$ 2586). Fig. 1(a)-(d) each show randomly selected spaghetti plots or trajectories of protein intake relative to needs from actual individuals in the Cebu Longitudinal Health and Nutrition Survey. Four trajectories were derived using latent class growth curve analyses. (a) Subset of the 'normal consumers' who constituted $58 \%$ of the sample; (b) 'high consumers during infancy' ( $20 \%$; (c) 'usually high consumers' (18\%); (d) 'always high consumers' (5\%); (e) mean protein intake relative to needs ( $\mathrm{g} / \mathrm{kg}$ body weight) by trajectory with $95 \% \mathrm{Cl}$; (f) mean absolute protein intakes $(\mathrm{g})$ and standard deviations for those trajectories. - . _ ... Usually high consumers; _ _ always high consumers; ------, high consumers during infancy; - . - - , normal consumers. 
Table 2. Mean demographic characteristics overall and by trajectory classification

\begin{tabular}{|c|c|c|c|c|c|c|c|c|}
\hline Trajectories & $\begin{array}{l}\text { Maternal education } \\
\text { at birth (years) }\end{array}$ & $\begin{array}{l}\text { Maternal height } \\
\text { at birth }(\mathrm{cm})\end{array}$ & $\begin{array}{l}\text { Infant weight } \\
\text { at birth }(\mathrm{kg})\end{array}$ & Male & $\begin{array}{c}\text { BMl at age } \\
2 \text { years }\left(\mathrm{kg} / \mathrm{m}^{2}\right)\end{array}$ & $\begin{array}{l}\text { Assets at } \\
\text { age } 2 \text { years }\end{array}$ & $\begin{array}{l}\text { Urbanicity at } \\
\text { age } 2 \text { years }\end{array}$ & $\begin{array}{l}\text { Breast-feeding } \\
\text { duration (months) }\end{array}$ \\
\hline Overall & $7 \cdot 51$ & $150 \cdot 63$ & 3.00 & 0.52 & $15 \cdot 56$ & $2 \cdot 65$ & $28 \cdot 42$ & 13.53 \\
\hline Normal consumers & $6 \cdot 61$ & $150 \cdot 46$ & 3.01 & 0.50 & 15.59 & $2 \cdot 23$ & $25 \cdot 47$ & $15 \cdot 06$ \\
\hline High consumers in infancy & $9 \cdot 26$ & $151 \cdot 17$ & 3.01 & 0.50 & $15 \cdot 59$ & 3.46 & $33 \cdot 27$ & $10 \cdot 60$ \\
\hline Usually high consumers & 8.38 & $150 \cdot 64$ & 2.98 & 0.65 & $15 \cdot 55$ & 3.00 & 32.74 & $12 \cdot 12$ \\
\hline Always high consumers & $10 \cdot 11$ & $150 \cdot 68$ & 2.85 & 0.50 & $15 \cdot 03$ & 3.92 & 34.66 & 8.50 \\
\hline$F$ statistic $^{*}$ & 102.99 & 2.56 & 5.01 & 28.01 & $6 \cdot 35$ & $75 \cdot 18$ & $67 \cdot 17$ & 61.01 \\
\hline$P$ & $<0.001$ & 0.053 & 0.002 & $<0.001$ & $<0.001$ & $<0.001$ & $<0.001$ & $<0.001$ \\
\hline
\end{tabular}

* ANOVA for continuous variables or $x^{2}$ test for categorical variables (sex).

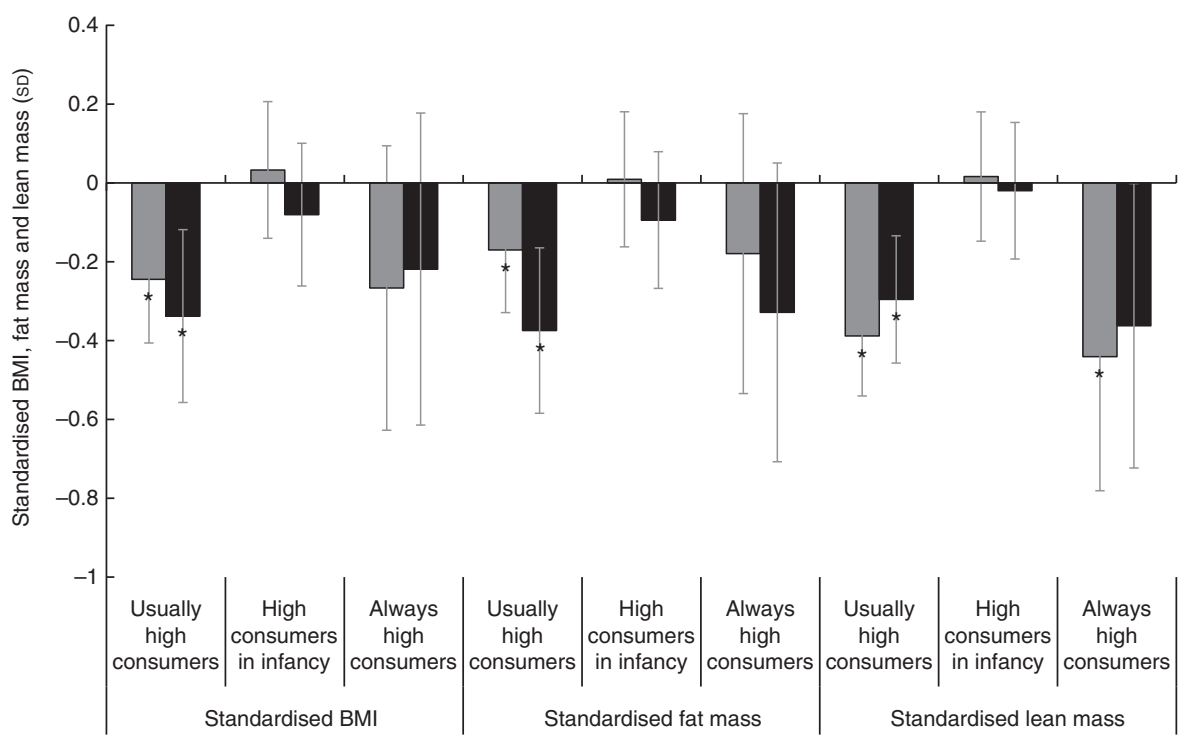

Fig. 3. Trajectories of protein intake are differentially associated with BMI, lean mass and fat mass at age 22 years in the Cebu Longitudinal Health and Nutrition Survey (CLHNS). Coefficients are derived from the regression of trajectories of protein intake from age 2 to 22 years on standardised BMI, fat mass and lean mass, adjusted for characteristics at birth (offspring weight, maternal education and maternal height), characteristics at age 2 years (offspring BMI and household assets), characteristics from age 22 years (offspring education and assets, physical activity level, carbohydrate residuals, fat residuals and energy intake). BMI, fat mass and lean mass at age 22 years were standardised to the mean of the sex-stratified sample of the CLHNS. Standardised outcomes for one sex in a given trajectory were compared to outcomes for the normal consumer trajectory for that sex. $\square$, Males; $\square$, females. ${ }^{\star} P<0.05$.

consumers served as the referent category in the sex-specific contrasts. 'Usually high' consumption was associated with lower BMI $(-0.244 \mathrm{SD} ; 95 \% \mathrm{CI}-0.406,-0.083 ; \beta$ equivalent to $-1.1 \mathrm{~kg} / \mathrm{m}^{2}$ and $-0.338 \mathrm{sD} ; 95 \%$ CI $-0.553,-0.122$ or $\beta-0.8 \mathrm{~kg} / \mathrm{m}^{2}$ in males and females, respectively). 'Usually high' consumption was also associated with lower fat mass $(-0.170 \mathrm{SD} ; 95 \% \mathrm{CI}-0.329,-0.011$ or $\beta-1.7 \mathrm{~kg}$ and $-0.374 \mathrm{sD}$; $95 \%$ CI $-0.594,-0.155$ or $\beta-0.8 \mathrm{~kg})$ and lower lean mass $(-0.388 \mathrm{sD} ; 95 \% \mathrm{CI}-0.541,-0.236$ or $\beta-1.7 \mathrm{~kg}$ and $-0.296 \mathrm{sD}$; $95 \%$ CI $-0.506,-0.086$ or $\beta-2.2 \mathrm{~kg}$ in males and females, respectively). 'Always high' consumption was associated with lower lean mass in males ( -0.441 sD; $95 \%$ CI $-0 \cdot 781,-0 \cdot 101$ or $\beta-2.6 \mathrm{~kg}$ ). In both sexes, high consumers during infancy were similar to normal consumers when BMI, lean mass and fat mass at age 22 years were compared. Similar inferences were drawn when the analytical sample was restricted to participants with data from at least three of five protein survey rounds. Inferences from the Heckman-corrected findings were similar to these results, but a significant association did emerge between high protein intake in infancy and both fat mass and BMI in females.

\section{Discussion}

In this study, protein intake from age 2 to 22 years had nuanced associations with body composition at age 22 years. Earlychildhood protein intakes were positively associated with later BMI and lean mass in females. However, protein intake from age 11 to 22 years tended to be inversely associated with later BMI, lean mass and fat mass. Of the four latent trajectories identified, trajectories marked by high adolescent and adult intakes of protein were associated with lower BMI, lean mass and fat mass at age 22 years.

A growing body of literature has associated infant or earlychildhood protein intake with risk of obesity in later childhood or even adulthood ${ }^{(5,6,9,34-36)}$. For example, protein intake $(\mathrm{g} / \mathrm{kJ}$ (g/kcal)) from 9 to 12 months was associated with higher BMI in 6 -year-old Icelandic males ${ }^{(37)}$ whereas high protein intake $(\mathrm{g} / \mathrm{kJ}$ (g/kcal)) in 12-month-old German males was associated with higher BMI at age 7 years ${ }^{(38)}$. Our current findings lend credence to the early protein-later BMI hypothesis.

However, our analyses differed from previously published studies in several ways. First, published studies conducted 
associations with BMI and did not include measures of lean or fat mass as we did here; it is unclear whether their associations with BMI also extended to adiposity or lean mass. Our results indicate that early protein was associated with higher female BMI and lean mass, but not fat mass. In this low-income cohort, this could also be interpreted as females who were better nourished in early life being less stunted and underweight as adults. Infant protein intake also programmes linear growth, an association potentially mediated by the insulin-like growth factor $^{(39,40)}$. A recent study in this Cebu cohort did find that childhood protein intakes (g) were positively associated with attained height at age 22 years ${ }^{(41)}$. As protein is associated with both lean and fat mass, it is important to explicitly investigate whether associations with BMI are due to lean mass, fat mass or both, as we did here.

Second, unlike other cohorts in which similar analyses were conducted, this Filipino cohort had high prevalence of infant undernutrition and the infant diet tended to be poor in quality (low in animal protein and rich in energy from grain-based porridges $)^{(42)}$. Differences in protein source and/or quality presumably drive the associations of protein intake with height ${ }^{(39)}$ and body size ${ }^{(38)}$. We recently showed that even within CLHNS, associations between protein intake and concurrent BMI vary for protein from animal and plant sources $^{(43)}$. The dietary differences in our cohort may have contributed to the null associations observed for early protein intake with later BMI, lean mass and fat mass in males, and fat mass in females.

We also found that protein intakes (from ages 11 to 22 years) were strongly and inversely associated with lean mass, fat mass and BMI in both sexes. A study in a German cohort reported positive associations of animal protein intake at around the time of the adiposity rebound with men's adulthood fat-free mass ${ }^{(44)}$. During infancy, BMI tends to increase during the first year of life and then declines until age 3-5 years, after which it 'rebounds' the adiposity rebound is this increase in BMI following the minimal point or nadir seen in the BMI growth charts of children. As the CLHNS was not conducted during this period, we were unable to directly compare results with this study. Nevertheless, in this same German cohort, protein intake after infancy tended to be positively associated with later lean mass: tertiles of pubertal (between 9 and 15 years) energy-adjusted animal protein intake were associated with higher women's fatfree mass at $18-25$ years ${ }^{(44)}$. These findings contradict ours. Differences in diet quality may again help to explain why our findings vary. In addition, we expressed protein in $\mathrm{g} / \mathrm{kg}$ body weight and this specification may also explain why the results were not fully concordant with earlier studies that expressed protein intake in absolute grams or percentiles. Future studies should clarify how protein relative to needs, absolute protein intake as well as protein quality relates to later adulthood body size.

Our trajectory analyses also suggest that adolescent and adult intakes drove differences in body composition: trajectories characterised by higher protein intakes at age 22 years were consistently associated with lower BMI, fat mass and lean mass but body composition of the high infant trajectory was similar to the normal-consumption category. The estimated age-specific association of the early childhood diet with adult body size was relatively much smaller in magnitude compared with later years. Indeed, the Heckman-weighted, inverse associations that emerged between the trajectory of high protein intake in infancy and fat mass and BMI in females conflict the early protein hypothesis. Future studies should account for diet throughout the life course, so the relative contribution of protein intake at different ages to later body size is not missed.

These findings must be contextualised within the greater limitations of this study. First, as this study was conducted in an observational cohort, the findings presented here are associational and are not causal. We attempted to control for factors that were related to the protein intake variables and body size outcomes, but it is possible that omitted factors (such as the quality or source of protein) or poorly measured confounders may leave our estimates residually confounded. Second, in this rapidly urbanising society, the study sample decreased from 3080 at birth, to 2456 individuals at 24 months and 1885 participants at 22 years $^{(14)}$. We found that Heckman-corrected findings were generally similar to the results reported here. Nevertheless, there is still potential for selection bias if participants and those who were lost to follow-up varied based on unmeasured factors.

The third limitation is that we were unable to include dietary data from birth to 2 years. The inclusion of infant intakes would have facilitated comparisons with other DOHaD studies of the early protein hypothesis. As breastmilk nutrients were not quantified, the use of infant nutrient data would have underestimated total protein intake. Dietary data from infancy and at the time of the adiposity rebound may have improved trajectory derivation and strengthened these life-course analyses. Finally, the latent class trajectories derived here are driven by the unique socioeconomic and dietary characteristics of this population. Whereas the insights are valuable, they may not be generalisable to other populations.

Despite its limitations, this is an important methodological contribution to the life-course epidemiology literature. Ours is one of few studies to classify longitudinal dietary exposures and relate them to later health. Only one other study has analysed trajectories of dietary protein; in this German cohort, researchers classified individuals into trajectories of below/above the median protein intakes at ages 12 and 18-24 months. They found that high protein intake at both time-points was associated with significantly greater standardised BMI and percentage body fat at age 7 years ${ }^{(28)}$. Although this study captured the early life exposures that we were unable to include here, the crude derivation of trajectories, short follow-up period and childhood outcome clearly limit its generalisability. To our knowledge, only one other study has analysed a macronutrient across such a wide breadth of the life course: researchers used cluster analysis to isolate fat-intake patterns from 2 to 18 years in a German cohort ${ }^{(45)}$; they later found that these patterns did not explain later BMI ${ }^{(46)}$. Another study of Chinese adults used latent class trajectory analysis to group individuals according to a dietary-pattern score, they found that those with healthier dietary patterns had lower HbA1c, and when trajectories with recent healthy dietary patterns were compared, those who had prolonged recent exposure to a healthy dietary pattern had 
lower HbA1c compared with those who whose trajectory showed recent improvements in dietary pattern ${ }^{(47)}$. These longitudinal perspectives grant insights into the potentially cumulative role of diet in later health. The novelty of our study is that we were able to demonstrate how both varied patterns of protein intake and period-specific exposures were associated with later body composition within a single cohort.

Overall, our study supports long-term associations of protein intake with late BMI. However, more research is needed to clarify whether these associations are also present in other socioeconomic contexts. Analysis of comprehensive dietary data from multiple time-points and longer follow-up periods would further identify optimal ranges of age-specific protein intake for promoting later health and disease.

\section{Acknowledgements}

The authors express gratitude for the assistance of Dr Barry Popkin and Dr Allison Aiello for their insights throughout this project.

This study was funded by the Howard Hughes Medical Institute International Student Research Fellowship.

M. W. formulated the research questions, designed the study, analysed the data and wrote the article; L. A. provided the databases necessary; M. A. M., D. S.-A. and L. A. provided guidance in the analysis of data, the interpretation of findings and the critical revision of the manuscript; L. A. was responsible for the final content. All authors read and approved the final manuscript.

None of the authors has any conflicts of interest to declare.

\section{References}

1. Barker DJP (2007) The origins of the developmental origins theory. J Intern Med 261, 412-417.

2. Simpson SJ \& Raubenheimer D (2005) Obesity: the protein leverage hypothesis. Obes Rev 6, 133-142.

3. Institute of Medicine (2005) Dietary Reference Intakes for Energy, Carbohydrate, Fiber, Fat, Fatty Acids, Cholesterol, Protein, and Amino Acids (Macronutrients). Washington, DC: The National Academies Press.

4. Brabin B \& Coulter J (2003) Nutrition-associated disease. In Manson's Tropical Diseases, pp. 561-580 [J Farrar, NJ White, PJ Hotez, T Junghanss, D Lalloo and G Kang, editors]. London: Saunders.

5. Michaelsen KF, Larnkjær A \& Mølgaard C (2012) Amount and quality of dietary proteins during the first two years of life in relation to NCD risk in adulthood. Nutr Metab Cardiovasc Dis 22, 781-786.

6. Koletzko B, Broekaert I, Demmelmair H, et al. (2005) Protein intake in the first year of life: a risk factor for later obesity?: The EU childhood obesity project. Adv Exp Med Biol 569, 69-79.

7. Rolland-Cachera MF, Deheeger M, Maillot M, et al. (2006) Early adiposity rebound: causes and consequences for obesity in children and adults. Int J Obes (Lond) 30, S11-S17.

8. Rolland-Cachera MF, Deheeger M, Akrout M, et al. (1995) Influence of macronutrients on adiposity development: a follow up study of nutrition and growth from 10 months to 8 years of age. Int J Obes Relat Metab Disord 19, 573-578.
9. Hörnell A, Lagström H, Lande B, et al. (2013) Protein intake from 0 to 18 years of age and its relation to health: a systematic literature review for the 5 th Nordic Nutrition Recommendations. Food Nutr Res 57, 1-42.

10. Lind MV, Larnkjaer A, Molgaard C, et al. (2017) Dietary protein intake and quality in early life: impact on growth and obesity. Curr Opin Clin Nutr Metab Care 20, 71-76.

11. Westerterp-Plantenga MS (2008) Protein intake and energy balance. Regul Pept 149, 67-69.

12. Pesta DH \& Samuel VT (2014) A high-protein diet for reducing body fat: mechanisms and possible caveats. Nutr Metab (Lond) 11, 53.

13. Simpson SJ \& Batley R (2003) Geometric analysis of macronutrient intake in humans: the power of protein? Appetite $\mathbf{4 1}$, 123-140.

14. Drewnowski A \& Popkin BM (1997) The nutrition transition: new trends in the global diet. Nutr Rev 55, 31-43.

15. Popkin BM (1999) Urbanization, lifestyle changes and the nutrition transition. World Dev 27, 1905-1916.

16. Popkin BM \& Gordon-Larsen P (2004) The nutrition transition: worldwide obesity dynamics and their determinants. Int $J$ Obes Relat Metab Disord 28, S2-S9.

17. Popkin BM, Adair LS \& Ng SW (2012) Global nutrition transition and the pandemic of obesity in developing countries. Nutr Rev 70, 3-21.

18. Abdullah A (2015) The double burden of undernutrition and overnutrition in developing countries: an update. Curr Obes Rep 4, 337-349.

19. Tzioumis E \& Adair L (2014) Childhood dual burden of underand overnutrition in low- and middle-income countries: a critical review. Food Nutr Bull 35, 230-243.

20. Schooling C (2015) Life course epidemiology: recognising the importance of puberty. I Epidemiol Community Health 69 , 820.

21. Viner R, Ross D, Hardy R, et al. (2015) Life course epidemiology: recognising the importance of adolescence. J Epidemiol Community Health 69, 719-720.

22. Darnton-Hill I, Nishida C \& James W (2004) A life course approach to diet, nutrition and the prevention of chronic diseases. Public Health Nutr 7, 101-121.

23. Ben-Shlomo Y \& Kuh D (2002) A life course approach to chronic disease epidemiology: conceptual models, empirical challenges and interdisciplinary perspectives. Int J Epidemiol 31, 285-293.

24. Adair LS, Hindin MJ, Popkin BM, et al. (2011) Cohort profile: the Cebu longitudinal Health And Nutrition Survey. Int J Epidemiol 40, 619-625.

25. Food and Nutrition Research Institute (1980) Food Composition Tables. Manila: Department of Science and Technology.

26. World Health Organization (2012) Global Physical Activity Questionnaire (GPAQ) Analysis Guide. Geneva: WHO

27. Deurenberg P \& Deurenberg-Yap M (2003) Validity of body composition methods across ethnic population groups. Acta Diabetol 40, s246-s249.

28. Jones BL \& Nagin DS (2013) A note on a Stata plugin for estimating group-based trajectory models. Sociol Methods Res 42, 608-613.

29. Nagin DS (1999) Analyzing developmental trajectories: a semiparametric, group-based approach. Psychol Methods $\mathbf{4}$, 139-157.

30. Louvet B, Gaudreau P, Thompson A, et al. (2009) Latent Class Growth Modelling: a tutorial. Tutor Quant Methods Psychol 5 , $11-24$.

31. Jones BL, Nagin DS \& Roeder KA (2001) SAS procedure based on mixture models for estimating developmental trajectories. Sociol Methods Res 29, 374-393. 
32. Jones BL (2005) Traj group-based modeling of longitudinal data. https://www.andrew.cmu.edu/user/bjones/index.htm (accessed January 2016).

33. Heckman J (1979) Sample selection bias as a specification error. Econometrica 47, 153-161.

34. Koletzko B, Dobrzanska A, Sengier A, et al. (2009) Lower protein in infant formula is associated with lower weight up to age 2 y: a randomized clinical trial. Am J Clin Nutr 89, 1836-1845.

35. Weber M, Grote V, Closa-Monasterolo R, et al. (2014) Lower protein content in infant formula reduces BMI and obesity risk at school age: follow-up of a randomized trial. Am J Clin Nutr 99, 1041-1051.

36. Pimpin L, Jebb S, Johnson L, et al. (2016) Dietary protein intake is associated with body mass index and weight up to $5 \mathrm{y}$ of age in a prospective cohort of twins. Am J Clin Nutr 103, 389-397.

37. Gunnarsdottir I \& Thorsdottir I (2003) Relationship between growth and feeding in infancy and body mass index at the age of 6 years. Int J Obes Relat Metab Disord 27, 1523-1527.

38. Günther ALB, Remer T, Kroke A, et al. (2007) Early protein intake and later obesity risk: Which protein sources at which time points throughout infancy and childhood are important for body mass index and body fat percentage at $7 \mathrm{y}$ of age? $\mathrm{Am}$ J Clin Nutr 86, 1765-1772.

39. Hoppe C, Udam TR, Lauritzen L, et al. (2004) Animal protein intake, serum insulin-like growth factor I, and growth in healthy 2.5-y-old Danish children. Am J Clin Nutr 80, 447-452.

40. Putet G, Labaune J, Mace K, et al. (2016) Effect of dietary protein on plasma insulin-like growth factor-1, growth, and body composition in healthy term infants: a randomised, double-blind, controlled trial (Early Protein and Obesity in Childhood (EPOCH) study). BrJ Nutr 115, 271-284.

41. Bhargava A (2016) Protein and micronutrient intakes are associated with child growth and morbidity from infancy to adulthood in the Philippines. J Nutr 146, 133.

42. Wright MJ, Bentley M, Mendez M, et al. (2015) The interactive association of dietary diversity scores and breast-feeding status with weight and length in Filipino infants aged 6-24 months. Public Health Nutr 18, 1762-1773.

43. Wright M, Mendez MA, Sotres-Alvarez D, et al. (2016) Breastfeeding and protein intake influence body mass index from 2 months to 22 years in the Cebu Longitudinal Health and Nutrition Survey. J Nutr 146, 2085-2092.

44. Assmann KE, Joslowski G, Buyken AE, et al. (2013) Prospective association of protein intake during puberty with body composition in young adulthood. Obesity (Silver Spring) 21, E782-E789.

45. Alexy U, Schultze-Pawlitschko V, Sichert-Hellert W, et al. (2005) Cluster analysis of individuals with similar trends of fat intake during childhood and adolescence: a new approach to analyzing dietary data. Nutr Res 25, 251-260.

46. Alexy U, Sichert-Hellert W, Kersting M, et al. (2004) Pattern of long-term fat intake and BMI during childhood and adolescence-results of the DONALD Study. Int J Obes Relat Metab Disord 28, 1203-1209.

47. Batis C, Mendez MA, Sotres-Alvarez D, et al. (2014) Dietary pattern trajectories during 15 years of follow-up and HbA1c, insulin resistance and diabetes prevalence among Chinese adults. J Epidemiol Community Health 68, 773-779. 